$7-7-2010$

\title{
Palladium(II)-Catalyzed Dicarboxymethylation of Chiral Allylic Alcohols: Chirality Transfer Affording Optically Active Diesters Containing Three Contiguous Chiral Centers
}

\author{
Othman Hamed \\ Patrick M. Henry \\ Daniel P. Becker \\ Loyola University Chicago, dbecke3@luc.edu
}

Follow this and additional works at: https://ecommons.luc.edu/chemistry_facpubs

Part of the Chemistry Commons

Author Manuscript

This is a pre-publication author manuscript of the final, published article.

\section{Recommended Citation}

Hamed, Othman; Henry, Patrick M.; and Becker, Daniel P.. Palladium(II)-Catalyzed Dicarboxymethylation of Chiral Allylic Alcohols: Chirality Transfer Affording Optically Active Diesters Containing Three Contiguous Chiral Centers. Tetrahedron Letters, 51, 27: , 2010. Retrieved from Loyola eCommons, Chemistry: Faculty Publications and Other Works, http://dx.doi.org/10.1016/j.tetlet.2010.04.105

This Article is brought to you for free and open access by the Faculty Publications and Other Works by Department at Loyola eCommons. It has been accepted for inclusion in Chemistry: Faculty Publications and Other Works by an authorized administrator of Loyola eCommons. For more information, please contact ecommons@luc.edu. c) (i) $\Theta$

This work is licensed under a Creative Commons Attribution-Noncommercial-No Derivative Works 3.0 License. (C) 2010 Elsevier 
Palladium(II)-Catalyzed Dicarboxymethylation

of Chiral Allylic Alcohols: Chirality Transfer Affording Optically Active Diesters Containing Three Contiguous Chiral Centers

Othman Hamed, Patrick M. Henry, ${ }^{\dagger}$ and Daniel P. Becker* Department of Chemistry, Loyola University Chicago

6525 N. Sheridan Road, Chicago, Illinois 60626, USA

Pd-catalyzed olefin dicarbonylation of chiral allylic alcohols with chirality transfer affords the chiral alcohol diesters contiguous chiral centers, in good to excellent diastereoselectivities (78-98\%).
Leave this area blank for abstract info.

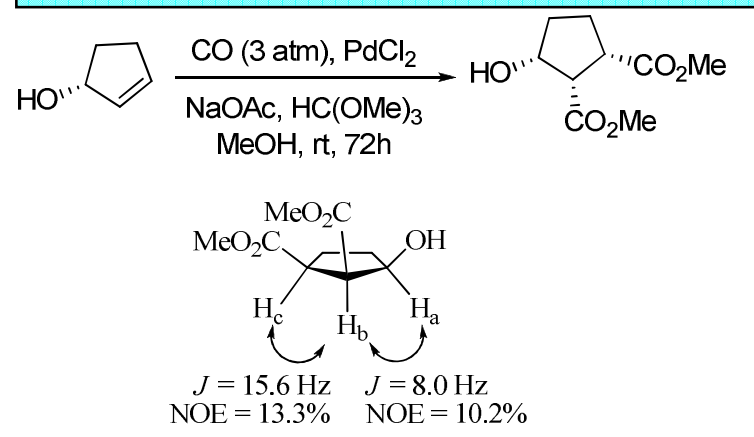




\title{
Palladium(II)-Catalyzed Dicarboxymethylation of Chiral Allylic Alcohols: Chirality Transfer Affording Optically Active Diesters Containing Three Contiguous Chiral Centers
}

\author{
Othman Hamed, Patrick M. Henry, ${ }^{\dagger}$ and Daniel P. Becker* \\ Department of Chemistry, Loyola University Chicago, 6525 N. Sheridan Road, Chicago, Illinois 60626, \\ USA
}

${ }^{\dagger}$ Deceased October 19, 2008.

\begin{abstract}
This manuscript describes the extension of Stille's palladium-catalyzed olefin dicarbonylation reaction to chiral allylic alcohols with chirality transfer to afford the corresponding chiral alcohol functionalized with bis-carbomethoxy esters, containing three contiguous chiral centers, in good to excellent diastereoselectivities (78-98\%).

\section{Introduction}

Enantiopure chiral materials are of key importance, particularly in the preparation of bioactive pharmaceuticals and more recently in liquid crystals, and palladium catalysis can be used in the construction of new asymmetric centers, either asymmetric catalysis or through the intramolecular transfer of existing chirality within a molecule. The directing influence of the hydroxyl group has been demonstrated for a number of reactions of chiral allylic alcohols, ${ }^{1-9}$ and stereoselectivities of over $98 \%$ have been demonstrated for some reactions. ${ }^{10-13}$ We presently wish to report the extension of chirality transfer from chiral allylic alcohols utilizing Stille's palladium-catalyzed olefin dicarbonylation reaction. ${ }^{14}$ In this context is it noteworthy that a number of groups have explored the use of chiral catalysts with the Stille bis-alkoxycarbonylation for the asymmetric construction of chiral bis-esters. Inomata and coworkers recently reported the palladium-catalyzed asymmetric bis(alkoxycarbonylation) of cyclic olefins in the presence of copper triflate. ${ }^{15}$ Liang and coworkers have described a palladium- 
catalyzed asymmetric biscarbonylation of terminal olefins using chiral S,N-heterobidentate ligands. ${ }^{16}$ Takeuchi described a palladium-catalyzed asymmetric bis(alkoxycarbonylation) reaction of terminal olefins in the presence of copper(I) triflate using a chiral bioxazoline ligand to give optically active monosubstituted succinates with enantioselectivities up to $66 \%$ ee, ${ }^{17}$ while Sperrle reported the enantioselective bis-alkoxycarbonylation of 1-olefins to substituted succinates using cationic palladium(II) complexes with C2 symmetric chelating ligands, and also the use of cationic palladium(II) complexes to catalyze multiple carbonylation of 1-olefins to 2-oxopentanedioates and to butanedioates. ${ }^{18}$ The dicarbonylation reaction is catalyzed by a $\mathrm{PdCl}_{2}-\mathrm{CuCl}_{2}$ system in methanol under basic conditions at low $\mathrm{CO}$ pressures $(3 \mathrm{~atm})$ to give diesters with an overall syn addition. ${ }^{19-27}$ While chirality transfer generally involves transfer of optical activity from one carbon to another, this allylic dicarbonylation that we now report involves a double insertion of $\mathrm{CO}$ to give diesters containing three contiguous chiral centers.

\section{Results and Discussion}

The bis-carbonylation with chirality transfer was first tested with the chiral cyclic allylic alcohol (R)-(+)cyclopent-2-en-1-ol ${ }^{28}(\mathbf{1})$. Cyclopent-2-enone underwent clean 1,2-reduction to afford compound (R)-(+)1 in $78.3 \%$ isolated yield and $71 \%$ ee by reduction with chiral (R)-oxazaborolidine ${ }^{29-31}$ and borane. Kita reported a similar asymmetric reduction of a cyclic enone with an oxazaborolidine ${ }^{32}$ and Matusuo recently reported the oxazaborolidine-catalyzed asymmetric reduction of $\alpha$-methylene ketones using boranediethylaniline as a stoichiometric reducing agent. ${ }^{33}$ The absolute configuration of $\mathbf{1}$ was determined based upon measurement of rotation and comparison with literature values. ${ }^{34}$ Treatment of of (R)-(+)-1 with $\mathrm{PdCl}_{2}$ and $\mathrm{CuCl}_{2}$ in methanol at room temperature under an atmosphere of $\mathrm{CO}(3 \mathrm{~atm})$ in the presence of trimethyl orthoformate to remove adventitious water gave two products in $65 \%$ and $35 \%$ relative yields as determined by gas chromatography. The two products were identified by ${ }^{1} \mathrm{H}$ and ${ }^{13} \mathrm{C}$ NMR to be (1S,2S,3R)-dimethyl 3-hydroxycyclopentane-1,2-dicarboxylate (2) and (S)-methyl 3oxocyclopentanecarboxylate (3), respectively (Scheme 1). The e.e. of 2 was established to be $69.7 \%$ as determined by ${ }^{1} \mathrm{H}$ NMR in the presence of lanthanide shift reagent $\mathrm{Eu}(\mathrm{hcf})_{3}$, thus the reaction proceeded 
in $98 \%$ diastereoselectivity (Table 1), representing the efficiency of chirality transfer from the asymmetric carbinol center. As noted, allylic alcohol (R)-(+)-1 was utilized with $71 \%$ ee, such that complete diastereoselectivity in the bis-alkoxycarbonylation would yield diester of e.e. identical to the starting allylic alcohol. The relative stereochemistry of the dicarbonylation product 2 was established by ${ }^{1} \mathrm{H}$ NMR, and NOE studies. The $J$ values of $\mathrm{H}_{\mathrm{b}}$ with $\mathrm{H}_{\mathrm{a}}$ and $\mathrm{H}_{\mathrm{c}}$, respectively are 8.0 and $15.6 \mathrm{~Hz}$. These values are consistent with the syn stereochemistry between $\mathrm{H}_{\mathrm{a}}, \mathrm{H}_{\mathrm{b}}$ and $\mathrm{H}_{\mathrm{c}}$. Since the absolute configuration at $\mathrm{C}-1$ is known to be $R$, the absolute configuration at $\mathrm{C}-1$ and $\mathrm{C}-2$, bearing the carbomethoxy groups, must both be $S$. The relative stereochemistries of $\mathrm{H}_{\mathrm{a}}, \mathrm{H}_{\mathrm{b}}$ and $\mathrm{H}_{\mathrm{c}}$ were also confirmed on the basis of NOE studies_(Figure 1). The all-syn relative stereochemistry evident by the $10.2 \%$ enhancement of the signal for $\mathrm{H}_{\mathrm{a}}$ upon irradiation of $\mathrm{H}_{\mathrm{b}}$ and the $13.3 \%$ enhancement of the signal for $\mathrm{H}_{\mathrm{c}}$. The cis stereochemistry is as predicted for the double-carbonylation reaction. ${ }^{35}$

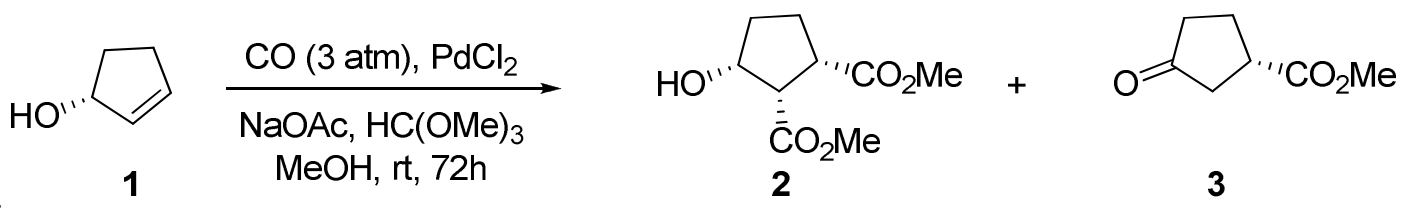

Scheme 1. Dicarbonylation of (R)-(+)-1

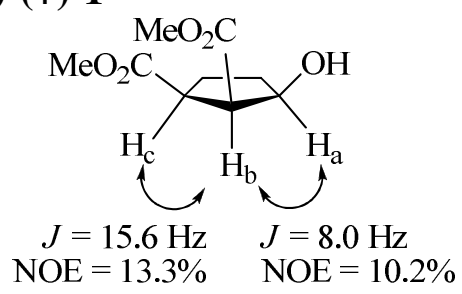

Figure 1. Confirmation of all-cis stereochemistry of dicarbonylated product $\mathbf{2}$ based on vicinal coupling constants and NOE correlations.

The product distribution and relative stereochemistries are consistent with the proposed mechanism (Scheme 2), similar to the mechanism proposed by Uenishi ${ }^{13}$ for an intramolecular palladium(II)catalyzed oxypalladation and 1,3-chirality transfer. Thus, the hydroxyl group directs the palladium to the face that produces the most stable $\pi$-complex $\mathbf{4}$, which in turn depends on the absolute configuration of the starting allylic alcohol 1. ${ }^{4}$ 10-13 Addition of carbon monoxide to complex $\mathbf{4}$ followed by insertion of 
methanol yields the olefin-carbomethoxypalladium intermediate 5, which undergoes insertion of the carbomethoxy group to produce the $\sigma$-complex $6{ }^{14,19}$ Adduct $\mathbf{6}$ then either undergoes further syn addition of $\mathrm{CO}$ to give desired $\mathbf{2}$, or loses a proton and eliminates palladium yielding an enol which tautomerizes to ketone 3 .

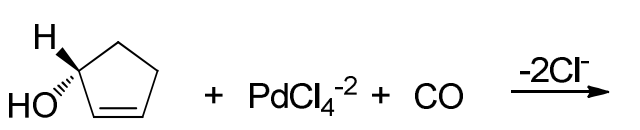
$(\mathrm{R})-(+)-1$

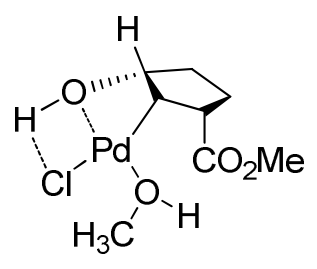

6

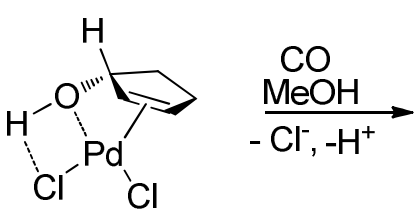

4<smiles>COC[C@H]1CCC[C@@H]1C(OC)OC</smiles>

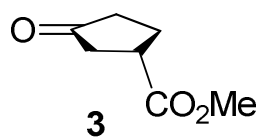

Scheme 2. Proposed mechanism for the palladium-catalyzed bis-alkoxycarbonylation of allylic alcohols with chirality transfer.

Next we examined the carbomethoxylation of (R)-(Z)-pent-3-en-2-ol [(Z)-9] and (E)-pent-3-en-2-ol [(E)-9]. Both isomers were prepared from the reduction of (R)-(+)-pent-3-yn-2-ol (8) (Scheme 3). (R)(+)-pent-3-yn-2-ol (8) was prepared in 85\% yield by the reduction of 3-pentyn-2-one 7 with chiral (S,S)$\mathrm{RuCl}[N$-(tosyl)-1,2-diphenylethylenediamine)(p-cymene)] reagent in formic acid/triethylamine isotropic mixture according to the general method of Bogliotti. ${ }^{36}$ A sample of $(\mathrm{R})-(Z)-9$ was prepared in $86 \%$ ee by reduction of the triple bond with Lindlar's catalyst ${ }^{37}$ while $(\mathrm{R})-(E)-9$ was prepared in $83 \%$ ee by reduction with $\mathrm{LiAlH}_{4}{ }^{38}$ GLC and ${ }^{1} \mathrm{H}$ NMR analysis showed that each sample was greater than $95 \%$ of the desired double bond geometric isomer. 
<smiles>[R]C#CC(C)=O</smiles>

$7 \mathrm{R}=\mathrm{CH}_{3}$ $11 \mathrm{R}=\mathrm{Ph}$<smiles>CC#CC(=O)c1ccccc1</smiles><smiles>CC#CC(=O)C(c1ccccc1)c1ccccc1</smiles>

16<smiles>[R]C#CC(C)O</smiles>

$8 \mathrm{R}=\mathrm{CH}_{3}$ $12 \mathrm{R}=\mathrm{Ph}$<smiles>CCCC(=O)c1ccccc1</smiles><smiles>CCCC(=O)C(c1ccccc1)c1ccccc1</smiles>
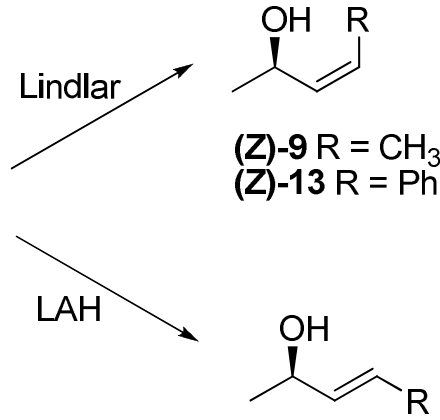

(E)-9 R $=\mathrm{CH}_{3}$ (E)-13 $R=P h$

Scheme 3. Preparation of $\mathrm{Z}$ and $\mathrm{E}$ allylic alcohols $\mathbf{9}$ and $\mathbf{1 3 .}$

Dicarbomethoxylation of each geometric isomer of $\mathbf{9}$ independently was carried out in the same manner as for the substrate (R)-(+)-1 (Table 1). (R)-(Z)-9 afforded three products as shown by GLC, which were identified by NMR spectroscopy to be the desired (2R,3R)-dimethyl 2-((R)-1-hydroxyethyl)-3methylsuccinate $[R, R, R)-10]$ in $80 \%$ relative yield, plus 4-methoxy-pentan-2-one in 10\% yield, and 4acetoxy-pentan-2-one in $10 \%$ yield. A pure sample of (R,R,R)-10 was obtained by gas chromatography and the enantiomeric excess was determined by ${ }^{1} \mathrm{H}$ NMR in the presence of chiral shift reagent, $\mathrm{Eu}(\mathrm{hfc})_{3}$ to be $82.7 \%$, thus the diastereoselectivity was $96 \%$. The dicarbonylation of (R)-(E)-9 afforded the desired dicarboxymethylation product (2R,3S)-dimethyl 2-((R)-1-hydroxyethyl)-3-methylsuccinate, (R,R,S)-10, in $45 \%$ relative yield, plus 4-methoxy-pentan-2-one, 4-acetoxy-pentan-2-one, and 4-carbomethoxypentan-2-one, and 5\%, 20\%, and 30\% relative yields, respectively. A pure sample of (R,R,S)-10 was collected by GLC and analyzed by ${ }^{1} \mathrm{H}$ NMR in the presence of the lanthanide shift reagent $\mathrm{Eu}(\mathrm{hcf})_{3}$ to establish an e.e. of $64.7 \%$, representing a diastereoselectivity of $78 \%$. The relative configurations of 
stereogenic centers in the carbonylated products (10) of (R)-(Z)-9 and R-(E)-9 were confirmed by NOE. NOE has been used previously to assign absolute configurations of cyclic systems ${ }^{39}$ and the theory for acyclic systems such as $\mathbf{9}$ with restricted rotation has also been presented. ${ }^{40}$ Shown in Figure 2 are the NOE assignments for the most stable rotamers of the two products. These assignments are in agreement with all the information from ${ }^{1} \mathrm{H}-{ }^{1} \mathrm{H}$ NOESY NMR. The assignment of absolute configuration is consistent with the expected initial syn addition of the elements of the carbomethoxy-Pd(II) moiety shown in Scheme 2.
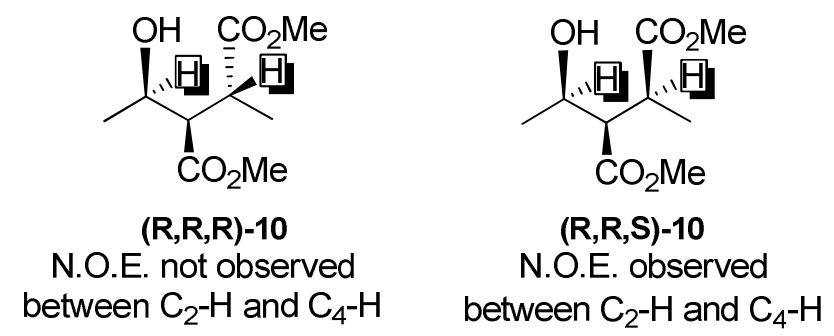

Figure 2 Assignment of relative stereochemistry of stereoisomers of $\mathbf{1 0}$ based on N.O.E.

Carbonylation of allylic alcohols (R)-(Z)-4-phenyl-but-3-ene-2-ol [(R)-(Z)-13] and (R)-(E)-4-phenyl3-buten-2-ol [(R)-(E)-13] were then evaluated. Propargyl alcohol 12 was prepared in 87\% ee with (R) absolute configuration by the reduction of propagyl ketone again using (S,S)-RuCl[N-(tosyl)-1,2diphenylethylenediamine)(p-cymene)] as outlined in Scheme 3. Allylic alcohol (R)-(Z)-13 was prepared in $87 \%$ ee by the reduction of the propagyl alcohol (R)-4-phenyl-but-3-yne-2-ol (12) using Lindlar's catalyst. Allylic alcohol (R)-(E)-13 was prepared in 75\% ee by the reduction of 12 using $\mathrm{LiAlH}_{4}$. Carbomethylation of $(\mathrm{R})-(\mathrm{Z}) \mathbf{- 1 3}$ afforded three products that were isolated and purified by flash chromatography. NMR analysis showed the compounds to be 4-methoxy-4-phenylbutan-2-one, 4acetoxy-4-phenyl-butan-2-one, and the desired (2R,3S)-dimethyl 2-((R)-1-hydroxyethyl)-3phenylsuccinate (R,R,S)-14, in $41 \%$ yield. The ee of (R,R,S)-14 was determined by ${ }^{1} \mathrm{H}$ NMR in the presence of the lanthanide shift reagent $\mathrm{Eu}(\mathrm{hcf})_{3}$ to be $80.7 \%$, representing a diastereoselectivity of $93 \%$. Dicarbomethoxylation of (R)-(E)-13 also produced three products, which were isolated and purified by 
flash chromatography. ${ }^{1} \mathrm{H}$ NMR analysis showed the compounds to be 4-methoxy-4-phenylbutan-2-one, 4-acetoxy-4-phenyl-butan-2-one, and the (2R,3R)-dimethyl 2-((R)-1-hydroxyethyl)-3-phenylsuccinate (R,R,R)-14 in 17\%, 27\% and 56\% yield, respectively. The diastereomeric ratio for (R,R,R)-14 was determined by ${ }^{1} \mathrm{H}$ NMR in the presence of the lanthanide shift reagent $\mathrm{Eu}(\mathrm{hcf})_{3}$ to be $64.7 \%$, thus the dicarbomethoxylation proceeded in $86 \%$ diastereoselectivity.

We also attempted to prepare (R)-1-phenyl-3-butyn-1-ol and (R)-1,1-dipheny-4-pentyne-2-ol utilizing (S,S)-RuCl[N-(tosyl)-1,2-diphenylethylenediamine)(p-cymene)] from the corresponding propargyl ketones $\mathbf{1 5}$ and 16, but only clean 1,4-reduction occurred as shown in Scheme 3. These results indicate that 1,2-reduction of propargyl ketone to chiral allylic alcohol using this chiral ruthenium reagent may be limited to propargyl ketones with a non-bulky group on the $\alpha$ carbon.

In summary, we have demonstrated the utilization of asymmetric dicarboxymethylation of allylic alcohols for the preparation of materials containing three contiguous asymmetric centers in good to excellent (78-98\%) diastereoselectivities.

Acknowledgement. Acknowledgment is made to the Donors of the American Chemical Society Petroleum Research Fund for support of this research through ACS PFR \#48511-AC1. NSF Grant DBI0216630 is gratefully acknowledged for the Varian INOVA-300 NMR obtained through the NSF Major Instrumentation Program, The authors also thanks Dr. Kyaw Zaw from the University of Illinois at Chicago (UIC) for running the NOESY experiment.

\section{References}

1. Stork, G.; Kahne, D. E. J Am Chem Soc. 1983, 105, 1072-1073.

2. Thompson, H. W.; Shah, N. V. J Org Chem. 1983, 48, 1325-1328.

3. Brown, J. M.; Naik, R. G. J Chem Soc, Chem Commun. 1982, 348-350.

4. Hamed, O.; Henry, P. M. Organometallics. 1997, 16, 4903-4909.

5. Stork, G.; Kahn, M. Tetrahedron Lett. 1983, 24, 3951-3954.

6. Cha, J. K.; Christ, W. J.; Kishi, Y. Tetrahedron Lett. 1983, 24, 3943-3946.

7. Czernecki, S.; Georgoulis, C.; Provelenghiou, C. Tetrahedron Lett. 1975, 2623-2626.

8. Czernecki, S.; Georgoulis, C.; Provelenghiou, C. Tetrahedron Lett. 1979, 4841-4844.

9. Smadja, W.; Czernecki, S.; Ville, G.; Georgoulis, C. Organometallics. 1987, 6, 166-169. 
10. Francis, J. W.; Henry, P. M. Organometallics. 1991, 10, 3498-3503.

11. Francis, J. W.; Henry, P. M. Organometallics. 1992, 11, 2832-2836.

12. Hamed, O.; Thompson, C.; Henry, P. M. J Org Chem. 1997, 62, 7082-7083.

13. Uenishi, J.; Vikhe, Y. S.; Kawai, N. Chem --Asian J. 2008, 3, 473-484.

14. Stille, J. K.; Divakaruni, R. J Org Chem. 1979, 44, 3474-3482.

15. Aratani, T.; Tahara, K.; Takeuchi, S.; Ukaji, Y.; Inomata, K. Chem Lett. 2007, 36, 1328-1329.

16. Liang, B.; Liu, J.; Gao, Y.; Wongkhan, K.; Shu, D.; Lan, Y.; Li, A.; Batsanov, A. S.; Howard, J. A. H.; Marder, T. B.; Chen, J.; Yang, Z. Organometallics. 2007, 26, 4756-4762.

17. Takeuchi, S.; Ukaji, Y.; Inomata, K. Bull Chem Soc Jpn. 2001, 74, 955-958.

18. Sperrle, M.; Consiglio, G. Inorg Chim Acta. 2000, 300-302, 264-272.

19. James, D. E.; Stille, J. K. J Am Chem Soc. 1976, 98, 1810-1823.

20. Choi, D.; Lee, K.; Chung, Y.; Joo, J.; Kim, Y.; Oh, C.; Lee, Y.; Ham, W. Arch Pharm Res. 2005, 28, 151-158.

21. Bianchini, C.; Meli, A.; Oberhauser, W.; Parisel, S.; Gusev, O. V.; Kal'sin, A. M.; Vologdin, N. V.; Dolgushin, F. M. J Mol Catal A: Chem. 2004, 224, 35-49.

22. Dai, M.; Wang, C.; Dong, G.; Xiang, J.; Luo, T.; Liang, B.; Chen, J.; Yang, Z. Eur J Org Chem. 2003, 4346-4348.

23. Parvulescu, V.; Constantin, C.; Su, B. L. J Mol Catal A: Chem. 2003, 202, 171-178.

24. Mizutani, T.; Ukaji, Y.; Inomata, K. Bull Chem Soc Jpn. 2003, 76, 1251-1256.

25. Yokota, T.; Sakaguchi, S.; Ishii, Y. J Org Chem. 2002, 67, 5005-5008.

26. Bianchini, C.; Lee, H. M.; Mantovani, G.; Meli, A.; Oberhauser, W. New J Chem. 2002, 26, 387-397.

27. Hayashi, M.; Takezaki, H.; Hashimoto, Y.; Takaoki, K.; Saigo, K. Tetrahedron Lett. 1998, 39, 75297532.

28. Nuthakki, B.; Bobbitt, J. M.; Rusling, J. F. Langmuir. 2006, 22, 5289-5293.

29. Corey, E. J.; Bakshi, R. K.; Shibata, S.; Chen, C. P.; Singh, V. K. J Am Chem Soc. 1987, 109, 79257926.

30. Corey, E. J.; Bakshi, R. K.; Shibata, S. J Am Chem Soc. 1987, 109, 5551-5553.

31. Hull, K. G.; Visnick, M.; Tautz, W.; Sheffron, A. Tetrahedron. 1997, 53, 12405-12414.

32. Fujioka, H.; Matsuda, S.; Horai, M.; Fujii, E.; Morishita, M.; Nishiguchi, N.; Hata, K.; Kita, Y. Chem --Eur J. 2007, 13, 5238-5248.

33. Matsuo, J.; Kozai, T.; Nishikawa, O.; Hattori, Y.; Ishibashi, H. J Org Chem. 2008, 73, 6902-6904.

34. Fukazawa, T.; Hashimoto, T. Tetrahedron: Asymmetry. 1993, 4, 2323-2326.

35. James, D. E.; Hines, L. F.; Stille, J. K. J Am Chem Soc. 1976, 98, 1806-1809.

36. Bogliotti, N.; Dalko, P. I.; Cossy, J. Tetrahedron Lett. 2005, 46, 6915-6918.

37. Lindlar, H.; Dubuis, R. Org Synth. 1966, 46, No pp. given.

38. Grant, B.; Djerassi, C. J Org Chem. 1974, 39, 968-970.

39. Ziffer, H.; Bax, A.; Highet, R. J.; Green, B. J Org Chem. 1988, 53, 895-896.

40. de Riggi, I.; Virgili, A.; de Moragas, M.; Jaime, C. J Org Chem. 1995, 60, 27-31. 